\title{
Argatroban During Percutaneous Transluminal Coronary Angioplasty: Results of a Dose-Verification Study
}

\author{
Jean-Paul R. Herrman, 1 \\ Harry Suryapranata, ${ }^{2}$ Peter den Heijer, ${ }^{3}$ \\ Laurence Gabriël, ${ }^{4}$ Michael J. B. Kutryk, and \\ Patrick W. Serruys \\ ${ }^{1}$ Thoraxcenter, Rotterdam, the Netherlands; ${ }^{2}$ Ziekenhuis De \\ Weezenlanden, Zwolle, the Netherlands; ${ }^{3}$ Academisch Ziekenhuis \\ Groningen, the Netherlands; ${ }^{4}$ Synthelabo Recherche, Bagneux \\ Cédex, France
}

\begin{abstract}
Background. Thrombin is a key enzyme in thrombogenesis. In animals, specific antithrombotic therapy at the time of coronary angioplasty reduced the incidence of subacute occlusion and inhibited the restenosis response. Argatroban is a highly selective synthetic thrombin antagonist that binds in a competitive manner. This is a report of a dose-verification study, assessing the safety and feasibility of intravenous Argatroban administration in patients undergoing percutaneous transluminal coronary angioplasty. Methods. Before angioplasty an intravenous bolus of $30 \mu \mathrm{g} / \mathrm{kg}$ argatroban was administered, followed by a continuous infusion of $3.5 \mu \mathrm{g} / \mathrm{kg} / \mathrm{min}$ for 72 hours. Bolus injection was repeated, and the infusion rate was increased in order to achieve an activated coagulation time (ACT) of over $300 \mathrm{sec}-$ onds. Following interim analysis, the bolus and initial infusion rate for the subsequent treatment groups was determined. Study endpoints were the occurrence of adverse events, coagulation tests, and qualitative angiogram reading. Patients were monitored by continuous 12-lead electrocardiographic recording over 24 hours, and underwent control angiography 18-24 hours following angioplasty. Results. Four treatment groups, comprised of $2,8,9$, and 11 patients, respectively, were studied. The first two patients were excluded from analysis, since the initial dose was ineffective to attain an ACT-authorizing coronary angioplasty. The group with the highest dosage received a $250 \mu \mathrm{g} / \mathrm{kg}$ intravenous bolus of argatroban, followed by a 4 hour infusion of $15 \mu \mathrm{g} / \mathrm{kg} / \mathrm{min}$. At 4 hours the infusion rate was lowered to $3.8 \mu \mathrm{g} / \mathrm{kg} / \mathrm{min}$ and was continued for 68 hours without adjustment for catheter removal. The adverse event profile included myocardial infarction, aortocoronary bypass graft, bailout procedures, and repeat coronary angioplasty. Thrombin-time (TT), activated partial thromboplastin time (APTT), and prothrombin time (PT) were significantly related to argatroban plasma concentration, as demonstrated by regression analyses ( $R$-square $0.64,0.71$, and 0.84 , respectively). Prothrombin fragments 1 and 2 and thrombin-antithrombin III complex did not fit into a mathematical model, but showed slightly increased levels after reduction or cessation of the infusion rate. Conclusions. This dose-verification study, including 30 patients at four dose levels, indicated that argatroban infusion in coronary angioplasty patients can be administered safely, and results in an adequate and predictable level of anticoagulation.
\end{abstract}

Key Words. angioplasty, transluminal, percutaneous coronary, antithrombins, blood coagulation tests, clinical trials, coronary disease, dose-response relationship, treatment outcome, argatroban

Angioplasty of coronary narrowings greatly enlarges the arterial lumen. Nevertheless, the short-term therapeutic benefit of percutaneous transluminal coronary angioplasty (PTCA) can be limited by formation of mural thrombus and subsequent abrupt closure of the coronary artery. In addition, organization of mural thrombus and proliferation of smooth muscle cells lead to vessel restenosis, also adversely influencing medium- and long-term results. The central role of thrombin in these events is a result of its effects on the clotting cascade, leading to fibrin and thrombus formation; on platelet aggregation, causing the liberation of growth factors; and finally its direct mitogenic effect on smooth muscle cells [1]. A low thrombin level is sufficient to activate phospholipid membrane bound factor V, which is part of the prothrombinase complex, and can therefore strongly accelerate thrombin formation [2]. Interference with this positive feedback loop by potent and specific thrombin inhibition is a very effective antithrombotic strategy [3,4].

Argatroban, (2R,4R)-4-methyl-1-[N ${ }^{2}$-(3-methyl-1,

Address for correspondence: Patrick W Serruys, MD, PhD, FESC, FACC, Professor of Interventional Cardiology, Thoraxcenter, Erasmus University, Room Bd 418, P.0. Box 1738, 3000 DR Rotterdam, The Netheriands.

Received February 29, 1996; accepted in revised form March 14, 1996 
2,3,4-tetrahydro-8-quinolonyl)sulphonyl)-arginyl]-2piperidine carboxylic acid), is an arginine derivate that binds competitively to thrombin [5]. Compared with heparin, it has several potential advantages. Argatroban is synthetic and therefore has no natural inhibitors. It does not need antithrombin III as a cofactor, and it is non-antigenic. Heparin is a mixture of heterogenous sized depolymerized molecules, and therefore its bioactivity may vary depending on the particular lot. In contrast, the anticoagulant effect of argatroban is concentration dependent [6] and comprises both free and clot-bound thrombin.

Specific antithrombin therapy using argatroban has been shown to be superior to heparin treatment in numerous experimental animal models of arterial thrombogenesis [7-19]. At doses causing comparable prolongation of activated partial thromboplastin time (aPTT), argatroban has been demonstrated to be significantly more effective than heparin for the prevention of platelet-rich thrombotic occlusion in an animal model [20]. Several human trials with argatroban have been completed using dosage regimens up to 25 $\mathrm{mg} / \mathrm{hr}$ IV for 2 hours [21] or $20 \mathrm{mg} / \mathrm{hr}$ IV for 2 hours after a $10 \mathrm{mg}$ bolus [22]. These studies have demonstrated a moderate dose-dependent 4.5-fold increase in thrombin time and a 1.6-fold prolongation of aPTT, with no effect of concomitant aspirin administration. The doses administered in human studies were low compared with those used in animal models, and at these low doses the elimination half-life is 24 minutes [23]. Based on these findings, it was felt safe to investigate this drug in patients with a hypercoaguable condition, such as patients with unstable angina or undergoing PTCA.

Recently argatroban was infused over 4 hours in patients experiencing unstable angina pectoris [24]. Infusion of the drug $(0.5-5.0 \mu \mathrm{g} / \mathrm{kg} / \mathrm{min})$ resulted in a dose-dependent increase in the aPTT and effectively prevented recurrences of ischemic episodes. Notably, 9 out of 43 patients experienced an episode of unstable angina shortly after drug administration was terminated. The authors attributed this to a rebound phenomenon.

There has been limited experience with the use of argatroban in PTCA patients (Fitzgerald, data not published). In this study, 12 patients were randomized to receive either a bolus of $30 \mu \mathrm{g} / \mathrm{kg}$ argatroban, followed by an intravenous infusion of $2 \mu \mathrm{g} / \mathrm{kg} / \mathrm{min}$ over 2 hours, or a bolus injection of 10,000 IU of heparin and a subsequent 4 hour infusion of $1000 \mathrm{IU} / \mathrm{hr}$. In order to further define the optimal dose of argatroban for patients undergoing coronary angioplasty, the pre-Argaplasty trial was initiated. This dose-verification study was undertaken to assess the safety and feasibility of administration of argatroban in patients undergoing balloon angioplasty and to broaden our understanding of the response to the coagulation system to this agent.

\section{Methods}

\section{Study design}

This study was an open, nonrandomized doseverification study, carried out in three hospitals in the Netherlands. The study was conducted according to G.C.P. regulations. Patients were allocated to study medication after giving written, informed consent. This study assessed the safety and feasibility of the use of three different doses of argatroban (groups A, $B$, and $C$, respectively) in patients undergoing PTCA. Acetylsalicylate $(250 \mathrm{mg}$ intravenous) was administered just prior to angioplasty, and $160 \mathrm{mg}$ acetylsalicylate was administered orally for the next 3 days.

\section{Patient selection}

Patients with stable or unstable angina pectoris due to one or more angiographically significant lesions in the native coronary system amenable to balloon angioplasty were considered eligible for this study. The main exclusion criteria were acute myocardial infarction or thrombolytic therapy within 2 weeks prior to PTCA; current treatment with oral anticoagulant drugs; and history of peptic ulcer disease, upper gastrointestinal bleeding, or stroke.

\section{Coronary angiograms and angioplasty}

Coronary angiograms were obtained immediately before and after balloon angioplasty, and repeated 18-24 hours afterwards. To standardize the method of data acquisition and to ensure the exact reproducibility of the angiograms performed after the intervention and at follow-up, measures were taken as described earlier $[25,26]$. Choice of angioplasty device, balloon pressure, and duration of inflation were left to the discretion of the operator. All angiograms were read at Cardialysis B.V., Rotterdam, the Netherlands.

\section{Argatroban dose regimen and dose adjustment}

Argatroban was provided by Synthélabo Recherche (L.E.R.S.), Bagneux Cédex, France. Its clearance and half-life are $5.0 \pm 0.5 \mathrm{ml} / \mathrm{kg} / \mathrm{min}$ and $24.4 \pm 3.5$ minutes, respectively, in healthy volunteers. As argatroban is a photosensitive drug, it was dispensed in opaque ampules containing doses $0.5 \mathrm{mg} / \mathrm{ml}$. The maximum total daily authorized dose was $10 \mathrm{mg} / \mathrm{kg}$ body weight.

The first eight patients (group A) were to receive a bolus of $30 \mu \mathrm{g} / \mathrm{kg}$ argatroban, followed by a $3.5 \mu \mathrm{g} /$ $\mathrm{kg} /$ min infusion over the next 72 hours. When the activated clotting time (ACT) exceeded 300 seconds, angioplasty was authorized approximately 45 minutes after administration of the bolus and the start of argatroban infusion. For an ACT less than 300 seconds, an extra $30 \mu \mathrm{g} / \mathrm{kg}$ bolus was administered, and the rate of infusion was increased by $0.5 \mu \mathrm{g} / \mathrm{kg} / \mathrm{min}$ increments until the ACT exceeded 300 seconds. Following 
PTCA, the infusion rate was adjusted to maintain the aPTT between 100 and 120 seconds (2.5-3 times normal value) according to the adjustment algorithm shown in Table 1. Following interim analysis, the bolus and initial infusion rates for the adjacent treatment groups (group B and C) were determined.

The femoral sheath was removed after reduction of the infusion rate to a predetermined level of $2.0 \mu \mathrm{g} /$ $\mathrm{kg} / \mathrm{min}$, in order to obtain an aPTT of less than 80 seconds (less than twice normal value). One hour after sheath removal, infusion rates were restored to their previous setting. The patients were kept on strict bed rest for the next 24 hours.

\section{Study endpoints; evaluation of efficiency and safety}

Study endpoints were the occurrence of major adverse cardiac events and bleeding complications, electrocardiographic changes as detected by continuous 12-lead recording, coagulation test results, and qualitative angiogram interpretation. Safety was evaluated on the basis of occurrence of death, nonfatal myocardial infarction, revascularization procedures, and bleeding complications. All deaths were considered cardiac unless documented to the contrary. Myocardial infarction was diagnosed on the basis of new $Q$ waves (Minnesota Code [27]) or an increase in creatinine kinase of more than twice the upper limit of normal with a concomitant increase in myocardial bound fraction.

Bailout stenting was considered equivalent to coronary artery bypass grafting (CABG) if patency of the target vessel could not be maintained otherwise. If a stent was implanted electively after the initial angioplasty (i.e., not comprising a bailout procedure), this was considered to be equivalent to repeat angioplasty. Repeat angioplasty was defined as re-insertion of a guiding catheter followed by angioplasty at the previously dilated site. The occurrence of typical anginal symptoms or electrocardiographic evidence of myocardial ischemia at rest or during exercise in case of atypical anginal symptoms and an angiographic diameter stenosis of $>50 \%$ by visual inspection was required to justifty repeat angioplasty or bypass surgery. Bleeding was classified as major if it was overt and led to a hemoglobin fall of at least $5 \mathrm{~g} / \mathrm{dl}$ or $15 \%$ hematocrit; required transfusion of five or more units of whole blood or packed cells; or occurred intracranial, retroperitoneal, or into a major joint [28]. Minor bleeding was defined as overt, gross hematuria, or haematemesis, or if it led to a fall in haemoglobin of at least $3 \mathrm{~g} / \mathrm{dl}$, or at least $10 \%$ hematocrit. Hematuria was classified as macroscopic when clinically evident, and as microscopic in the presence of more than four erythrocytes per high-power field.

\section{Secondary endpoints}

Coronary angiograms were analyzed for TIMI flow assessment [29], as documented at recatheterization
Table 1. Argatroban adjustments after the angioplasty procedure according to aPTT values

\begin{tabular}{lll}
\hline $\begin{array}{l}\text { aPTT (sec) } \\
\times \text { normal } \\
\text { value (NV) }\end{array}$ & $\begin{array}{l}\text { Discontinuation } \\
\text { (duration } \\
\text { in min) }\end{array}$ & $\begin{array}{l}\text { Dose change in } \\
(\mu \mathrm{g} / \mathrm{kg} / \mathrm{hr})\end{array}$ \\
\hline$<80 \mathrm{sec}$ & - & $+1 \mu \mathrm{g} / \mathrm{kg} / \mathrm{min} \uparrow$ \\
$<2$ times NV & - & $+0.5 \mu \mathrm{g} / \mathrm{kg} / \mathrm{min} \uparrow$ \\
$80-100 \mathrm{sec}$ & - & No change \\
$2-2.5$ times NV & - & $-0.5 \mu \mathrm{g} / \mathrm{kg} / \mathrm{min} \downarrow$ \\
$101-120 \mathrm{sec}$ & - & $-1 \mu \mathrm{g} / \mathrm{kg} / \mathrm{min} \downarrow$ \\
$2.5-3.0$ times NV & - & $-2 \mu \mathrm{g} / \mathrm{kg} / \mathrm{min} \downarrow$ \\
$121-140 \mathrm{sec}$ & & \\
$3.0-3.5$ times NV & & \\
$141-160 \mathrm{sec}$ & & $\mathrm{min}$ \\
$3.5-4.0$ times NV & & \\
$>160 \mathrm{sec}$ & & $\mathrm{min}$
\end{tabular}

24 hours following balloon angioplasty. Continuous $12-$ lead electrocardiography over 24 hours was analyzed for inschemic episodes of recurrent ischemia, defined as at least $0.1 \mathrm{mV} \mathrm{ST-segment} \mathrm{elevation} \mathrm{for} \mathrm{at} \mathrm{least} 1$ minute. Finally, blood samples were taken at various points in time to assess the dose-response relationship of various coagulation parameters. Determination of ACT was done extemporaneously in the catheterization laboratory on whole blood samples. Bleeding time was performed at screening, 12 hours, and 72 hours after commencement of the study medication. Blood samples for activated partial thromboplastin time (APTT), prothrombin time (PT), thrombin time (TT, thrombin concentration 4-20 IU/ml), thrombinantithrombin-complex (TAT), and prothrombin fragments 1 and $2\left(\mathrm{~F}_{1.2}\right)$ were drawn in the arm contralateral to that receiving medication. Those samples were centrally assessed in a hemostasis core lab.

\section{Statistical analysis}

Mainly descriptive statistics were carried out. Continuous variables were expressed as medians with their range, while categoric variables were expressed as absolute numbers and percentages. Two patients (group A) were not included in the statistical analysis, since the initial dose regimen, as specified in the protocol, was ineffective in terms of ACT. Regression analyses of the different coagulation parameters on argatroban plasma levels were performed. Linear models were fitted and expanded with a logarithmic, square, or cubic term.

\section{Results}

\section{Patient population and dose regimen}

The first two patients (group A) enrolled in the trial received a bolus of $30 \mu \mathrm{g} / \mathrm{kg}$ argatroban followed by an infusion of a rate of $3.5 \mu \mathrm{g} / \mathrm{kg} / \mathrm{min}$ in order to ob- 
tain an ACT balloon angioplasty of 300 seconds. However, despite repeated bolus injections and multiple increases in the infusion rate to $5.0 \mu \mathrm{g} / \mathrm{kg} / \mathrm{min}$, the ACT level did not exceed 200 seconds. Medication in these patients was replaced by routine (i.e., heparin) treatment.

Following detailed review of the first two patients, the next dosage group (group B) was assigned to receive a bolus of $60 \mu \mathrm{g} / \mathrm{kg}$, followed by a 4 hour infusion of $8 \mu \mathrm{g} / \mathrm{kg} / \mathrm{min}$. At 4 hours the infusion rate was lowered to $4 \mu \mathrm{g} / \mathrm{kg} / \mathrm{min}$ and was continued for 68 hours, so that the maximum daily dose would not be exceeded. In the absence of bleeding, no dosage adjustments were made. After recatheterization, the infusion rate was transiently reduced for catheter removal to $2.0 \mu \mathrm{g} / \mathrm{kg} / \mathrm{min}$, to achieve an aPTT level of less than twice the normal value. One hour after sheath removal, the infusion rate was restored. Eight patients were treated according to this schedule. Bleeding was not observed, ACT increased only moderately, and based on the results of $\mathrm{F}_{1.2}$ and TAT, a higher administration level was investigated.

In parallel with a phase I study carried out in nine healthy volunteers (unpublished data), the third dosage group (group C) received a bolus of $250 \mu \mathrm{g} / \mathrm{kg}$, followed by a 4 hour infusion of $10 \mu \mathrm{g} / \mathrm{kg} / \mathrm{min}$. At 4 hours the infusion rate was lowered to $3.8 \mu \mathrm{g} / \mathrm{kg} / \mathrm{min}$ and was continued for 68 hours. This dosage group comprised nine subjects. For sheath removal the same procedure was followed as in the foregoing patients. Evaluation of clinical data indicated satisfying safety levels, as bleeding was not observed. Furthermore, hemostatic parameters revealed that at 45 minutes thrombin generation was not totally controlled, and that reduction of the infusion rate to $2 \mu \mathrm{g} / \mathrm{kg} / \mathrm{min}$ for the sheath removal was accompanied by increased thrombin conversion and activity. Interim analysis demonstrated that the aPTT level, at an infusion rate of $3.8 \mu \mathrm{g} / \mathrm{kg} / \mathrm{min}$, was around twice the normal value. Based on these data, the patients in the fourth dosage group (group D) received a bolus of $250 \mu \mathrm{g} / \mathrm{kg}$, followed by a 4 hour infusion of $15 \mu \mathrm{g} / \mathrm{kg} / \mathrm{min}$. At 4 hours the infusion rate was lowered to $3.8 \mu \mathrm{g} / \mathrm{kg} / \mathrm{min}$ and was continued for 68 hours without adjustment for catheter removal. This dosage regimen group was comprised of 11 patiets who received a total daily dose of $8.4 \mathrm{mg} / \mathrm{kg}$. Demographic, clinical, and angiographic data of the patients studied are summarized in Tables 2 and 3, respectively. None of the patients had a history of bleeding or stroke. The small number of patients does not allow for comparison of the groups; however, the strict inclusion criteria ensure that they are very similar.

\section{Study endpoints (Table 4)}

In group $\mathrm{B}$, one patient experienced insignificant bleeding at the puncture site 7 hours after sheath removal during a $4 \mu \mathrm{g} / \mathrm{kg} / \mathrm{min}$ infusion, and therefore the study medication was discontinued. One case of
Table 2. Demographic data on the studied population per dosage group

\begin{tabular}{lccc}
\hline & $\begin{array}{c}\text { Group B } \\
(\mathrm{N}=8)\end{array}$ & $\begin{array}{c}\text { Group C } \\
(\mathrm{N}=9)\end{array}$ & $\begin{array}{c}\text { Group D } \\
(\mathrm{N}=11)\end{array}$ \\
\hline Male gender & $6(75 \%)$ & $5(56 \%)$ & $6(55 \%)$ \\
Caucasian & $7(88 \%)$ & $9(100 \%)$ & $11(100 \%)$ \\
Age (range) & $53(37-70)$ & $57(33-74)$ & $59(49-77)$ \\
Weight (range) & $76(62-105)$ & $65(60-85)$ & $72(56-92)$ \\
Previous MI & $2(25 \%)$ & $2(22 \%)$ & $5(45 \%)$ \\
Previous PTCA & $1(13 \%)$ & $5(56 \%)$ & $5(45 \%)$ \\
Previous CABG & $0(0.0 \%)$ & $1(11 \%)$ & $1(9 \%)$ \\
Hypertension & $3(38 \%)$ & $5(56 \%)$ & $4(36 \%)$ \\
NIDDM & $0(0.0 \%)$ & $2(22 \%)$ & $1(9 \%)$ \\
Hypercholesterolemia & $3(38 \%)$ & $4(44 \%)$ & $2(18 \%)$ \\
Current smoker & $2(25 \%)$ & $1(11 \%)$ & $2(18 \%)$ \\
Stable angina & $4(50 \%)$ & $6(67 \%)$ & $6(55 \%)$ \\
Unstable angina [40] & $4(50 \%)$ & $3(33 \%)$ & $5(45 \%)$ \\
$\quad$ Class I & 0 & 1 & 3 \\
$\quad$ Class II & 4 & 2 & 1 \\
$\quad$ Class III & 0 & 0 & 1 \\
Two-vessel disease & $1(12 \%)$ & $2(22 \%)$ & $2(18 \%)$ \\
\hline
\end{tabular}

Categorical variables are presented in absolute values and percent $\mathrm{N}(\%)$.

$\mathrm{MI}=$ myocardial infarction; PTCA $=$ percutaneous transluminal coronary angiography; $\mathrm{CABG}=$ coronary artery bypass graft surgery; NIDDM = non-insulin dependent diabetes mellitus; unstable angina class I-III $=$ according to the Braunwald classification [40].

phlebitis at the site of the indwelling infusion needle was reported, which occurred 58 hours after the commencement of the study medication.

In treatment group $\mathrm{C}$, two patients had a failed PTCA (one of which was a total occlusion before the attempt), and after discontinuation of argatroban infusion were referred for elective bypass surgery. Another patient showed recurrent stenosis $(>50 \%)$ with thrombus at the 24 hour control angiogram. Repeat PTCA (under argatroban therapy) was successful. In this group no bleeding complications were observed.

In treatment group $\mathrm{D}$, one patient experienced a myocardial infarction due to a subacute reocclusion. Repeat PTCA was attempted but not successful. Another patient showed recurrent stenosis $(>50 \%)$ on the 24 hour control angiogram. Repeat PTCA was not satisfactory, and a stent was implanted and argatroban was replaced with routine anticoagulants. During treatment with heparin and acenocoumarol, this patient had prolonged epistaxis, necessitating blood transfusion. A second repeat PTCA was performed in this patient for occlusion at the stented segment. In addition, a false aneurysm was reported in one patient, and prolonged insignificant bleeding at the puncture site in another.

There were no reported death or cases of hematuria in any of the four dose groups. Results of TIMI flow assessment and 12-lead electrocardiographic monitoring are reported in Tables 3 and 4, respectively. The low number of patients enrolled does not 
Table 3. Qualitative angiographic data on the studied population per dosage group

\begin{tabular}{|c|c|c|c|}
\hline $\begin{array}{l}\text { Treatment group } \\
\text { (No. lesions) }\end{array}$ & $\begin{array}{l}\text { Group B } \\
(\mathrm{N}=9)\end{array}$ & $\begin{array}{l}\text { Group C } \\
(\mathrm{N}=10)\end{array}$ & $\begin{array}{l}\text { Group D } \\
(\mathrm{N}=13)\end{array}$ \\
\hline Restenotic lesion & $1(11 \%)$ & $4(40 \%)$ & $4(31 \%)$ \\
\hline Total occlusion & $2(22 \%)$ & $1(10 \%)$ & $1(8 \%)$ \\
\hline \multicolumn{4}{|l|}{$\begin{array}{l}\text { Type of lesion (AHA/ } \\
\text { ACC) }\end{array}$} \\
\hline Type A & $1(11 \%)$ & $1(10 \%)$ & $1(8 \%)$ \\
\hline Type B1 & $3(33 \%)$ & 0 & $4(30 \%)$ \\
\hline Type B2 & $5(56 \%)$ & $9(90 \%)$ & $7(54 \%)$ \\
\hline Type C & 0 & 0 & $1(8 \%)$ \\
\hline \multicolumn{4}{|l|}{$\begin{array}{l}\text { TIMI flow } \\
\text { post-PTCA }\end{array}$} \\
\hline TIMI 0 & 0 & $1(10 \%)$ & $1(8 \%)$ \\
\hline TIMI I & 0 & 0 & 0 \\
\hline TIMI II & 0 & $1(10 \%)$ & 0 \\
\hline TIMI III & $9(100 \%)$ & $8(80 \%)$ & $12(92 \%)$ \\
\hline \multicolumn{4}{|l|}{ Dissections } \\
\hline Absent & $7(78 \%)$ & $5(50 \%)$ & $7(53 \%)$ \\
\hline Type A & $1(11 \%)$ & $1(10 \%)$ & $1(8 \%)$ \\
\hline Type B & 0 & $3(30 \%)$ & $4(31 \%)$ \\
\hline Type C & $1(11 \%)$ & $1(\mathbf{1 0 \%})$ & 0 \\
\hline Type D & 0 & 0 & $1(8 \%)$ \\
\hline Thrombus post-PTCA & 0 & $1(10 \%)$ & 0 \\
\hline \multicolumn{4}{|l|}{ TIMI flow at $24 \mathrm{hrs}$} \\
\hline TIMI 0 & 0 & 0 & $1(8 \%)$ \\
\hline TIMI I & 0 & $1(12 \%)$ & 0 \\
\hline TIMI II & 0 & 0 & 0 \\
\hline TIMI III & $9(100 \%)$ & $7(88 \%)$ & $10(84 \%)$ \\
\hline Not applicable & 0 & 0 & $1(8 \%)$ \\
\hline
\end{tabular}

Categorical variables are presented in absolute values and percent $\mathrm{N}(\%)$.

Table 4. Occurrence of clinical events per dosage group

\begin{tabular}{|c|c|c|c|}
\hline & $\begin{array}{l}\text { Group B } \\
(N=8)\end{array}$ & $\begin{array}{l}\text { Group C } \\
(\mathrm{N}=9)\end{array}$ & $\begin{array}{l}\text { Group D } \\
(\mathrm{N}=11)\end{array}$ \\
\hline Death & - & - & - \\
\hline MI & - & - & $1(9 \%)$ \\
\hline $\mathrm{CABG}$ & - & $2(22 \%)$ & - \\
\hline Bail-out & - & - & $1(9 \%)$ \\
\hline Repeat PTCA & - & $1^{\mathrm{a}}(11 \%)$ & $3^{a}(18 \%)$ \\
\hline Any event & $0(0 \%)$ & $3(33 \%)$ & $2(18 \%)$ \\
\hline $\begin{array}{l}\text { 12-lead ECG ST } \\
\text { monitoring }\end{array}$ & $8(100 \%)$ & $9(100 \%)$ & $11(100 \%)$ \\
\hline Patients with ST episodes & - & $1(11 \%)$ & $3(27 \%)$ \\
\hline Number of ST episodes ${ }^{b}$ & - & 0.9 & 2.9 \\
\hline $\begin{array}{l}\text { Duration of episodes } \\
\text { (median in min:sec) }\end{array}$ & - & $2: 33$ & $32: 07$ \\
\hline Epistaxis & - & - & $1(9 \%)$ \\
\hline False aneurysm & - & - & $1(9 \%)$ \\
\hline Bleeding at puncture site & $1(13 \%)$ & - & $1(9 \%)$ \\
\hline
\end{tabular}

The repeat PTCA in group B and one repeat PTCA in group C was triggered by the recatheterization 24 hours after the start of the infusion.

${ }^{b}$ Normalized to 24 hours recording time during treatment.

$\mathrm{MI}=$ myocardial infarction; $\mathrm{CABG}=$ coronary artery bypass graft surgery; PTCA = percutaneous transluminal coronary angiography. justify solid conclusions on angiographic and clinical results. Individual coagulation parameters may yield specific information on the unstable syndrome or complexity of the lesion, but this relationship remains speculative.

\section{Dose-response relationship of argatroban plasma level and coagulation parameters}

The relationships between argatroban plasma level and coagulation parameters (ACT, aPTT, TT, and PT) are presented in Figure 1. A clear dose-response relationship is documented for each parameter. Table 5 presents the results of linear regression analysis. Inclusion of a squared variable in the model (e.g., $\mathrm{y}=$ $a+b x+c^{2}$ ) for TT improved the R-square value from 0.639 to 0.653 . Additional inclusion of a cubed variable (e.g., $y=a+b x+c^{2}+d x^{3}$ ) in the aPTT model only marginally improved the $\mathrm{R}$-square value from 0.715 to 0.725 . Although these improvements in the models for TT and aPTT are statistically significant, we suggest restriction to the linear and square models, respectively, for pragmatic reasons. Logarithmic strategy in the aPTT model resulted in an $R$-square value of $0.64(p<0.001)$, which is inferior to the square model. No clear relationship could be detected between the argatroban plasma level and $\mathbf{F}_{1.2}$ and TAT concentrations (Figure 2); however, a substantial number of measurements exceeded the normal range $\left(1.29 \mathrm{nmol} / \mathrm{l}\right.$ for $\mathrm{F}_{1.2}$ and $3.2 \mu \mathrm{g} / \mathrm{kg} / \mathrm{l}$ for TAT).

\section{Discussion}

Argatroban was developed in Japan (MitsubishiDachii), where authorization for its use in the treatment of peripheral arterial disease was obtained in 1991 (MD-805, available as Novastan). The rationale for this study was based on the finding that specific antithrombin therapies can inhibit mural thrombosis after deep arterial injury and prevent the growth of pre-existing thrombus on deeply injured arteries exposed to both high and low shear stresses [8]. Experimentally, injured arteries remain highly thrombogenic for several hours to days following balloon injury [30-33]. Therefore, it was judged prudent to commence argatroban administration before the angioplasty procedure and to continue over the next 72 hours. The restriction of argatroban to intravenous administration limits its use to hospital setting.

The initial dosage was based on previous studies in cardiac patients. Gold and his colleagues infused argatroban $(0.5-5.0 \mu \mathrm{g} / \mathrm{kg} / \mathrm{min})$ over 4 hours in patients with unstable angina pectoris [24]. This dose regimen was effective against the recurrence of ischemic episodes. Fitzgerald (not published) treated angioplasty patients with an initial bolus of $30 \mu \mathrm{g} / \mathrm{kg}$ argatroban, followed by an intravenous infusion of 2 $\mu \mathrm{g} / \mathrm{kg} / \mathrm{min}$ over 2 hours. Based on toxicity studies in 


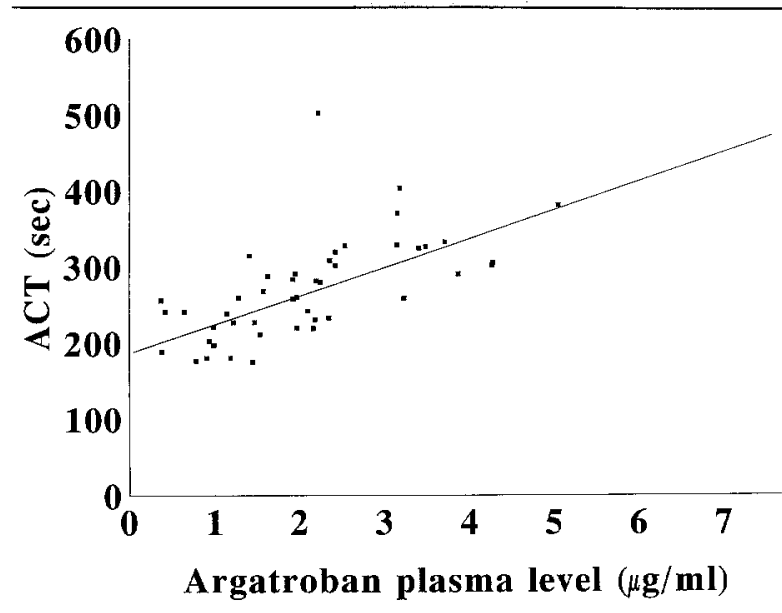

A

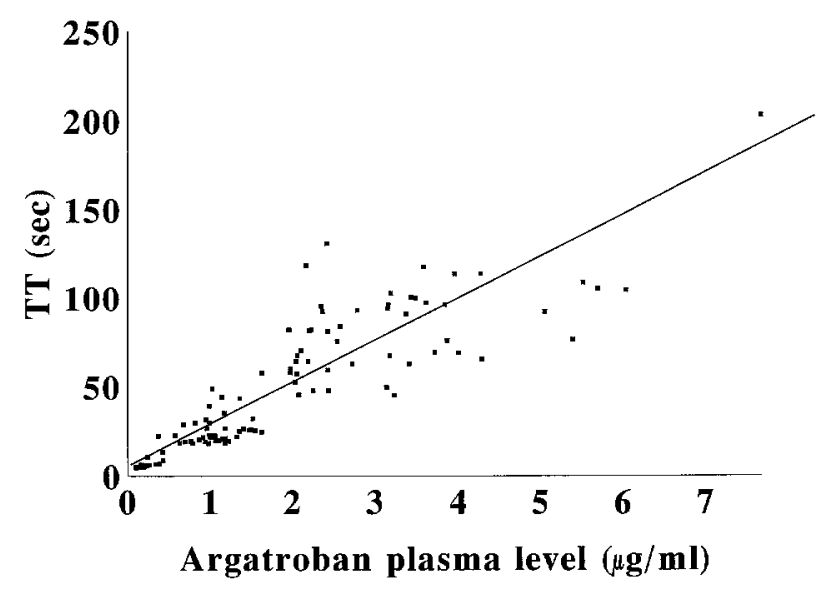

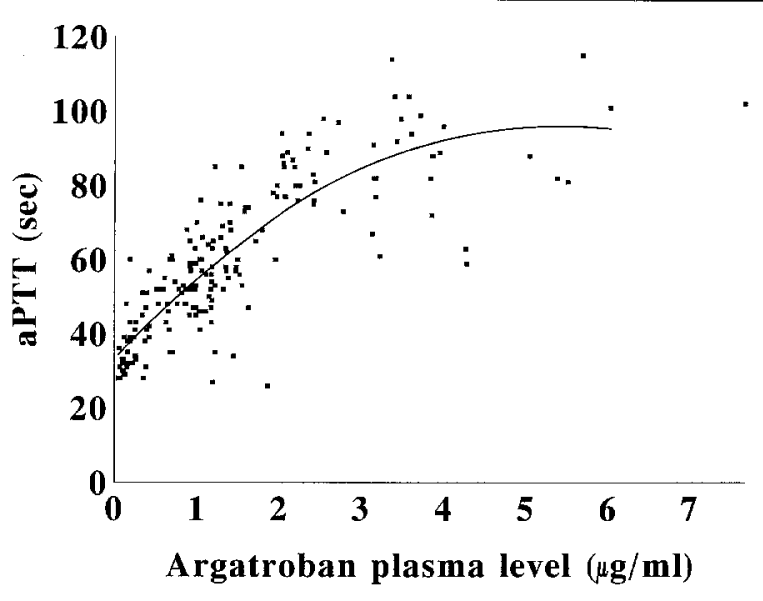

B

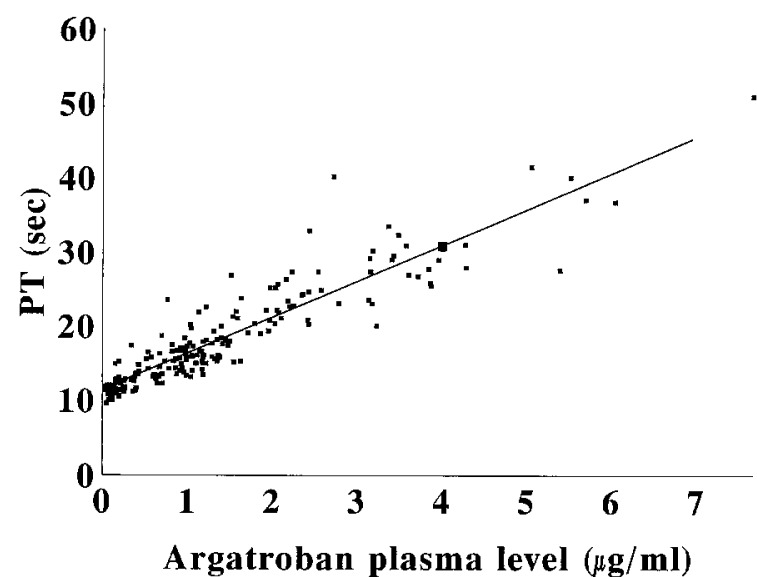

$\mathrm{D}$

Fig. 1. The relationship between argatroban plasma level and the result of coagulation tests. $A C T=$ activated clotting time; aPTT $=$ activated partial thromboplastin time; $T T=$ thrombin time; $P T=$ prothrombin time. The lines within the graphs outline the predicted levels of the models delineated in Table 5. A: ACT in seconds. B: aPTT in seconds. C: TT in seconds (thrombin concentration $20 \mathrm{IU} / \mathrm{ml}$ ). D: PT in seconds.

Table 5. Relationship between coagulation parameters and argatroban plasma level

\begin{tabular}{llll}
\hline & & & $\mathrm{R}$ \\
Parameter & Formula & p value & square \\
\hline BT & - & NS & 0.00 \\
ACT & $190+36.8 *$ APL & 0.000 & 0.54 \\
aPTT & $33.2+23.9 *$ APL $-2.25 *$ APL $^{2}$ & 0.000 & 0.71 \\
TT & $5.53+23.7 *$ APL & 0.000 & 0.64 \\
PT & $11.4+4.88 *$ APL & 0.000 & 0.84 \\
\hline
\end{tabular}

$\mathrm{APL}=$ Argatroban plasma level; $\mathrm{BT}=$ bleeding time; $\mathrm{ACT}=$ activated coagulation time; aPTT $=$ activated partial thromboplastin time; $\mathrm{TT}=$ thrombin time; $\mathrm{PT}=$ prothrombin time. animals, the total daily dose should not exceed $10 \mathrm{mg} /$ $\mathrm{kg}$ body weight.

A significant correlation was observed between the Argatroban plasma level and the dose-response curves for several coagulation parameters. The predictability of the aPTT and the PT, in particular, is very good and can be described mathematically with statistical significance. However, the predictability of bleeding time is low. Measurements of ACT with the Hemochron system yields values approximately $30 \%$ higher than the results assessed with HemoTec ACT assessment [34], which may have influenced the Rsquare value. The dose-response curves of argatroban and coagulation tests demonstrate the feasibility of accurate dosing of this compound in contrast to heparin, with which nonspecific plasma protein binding, variable bioavailability, nonlinear dose-dependent 


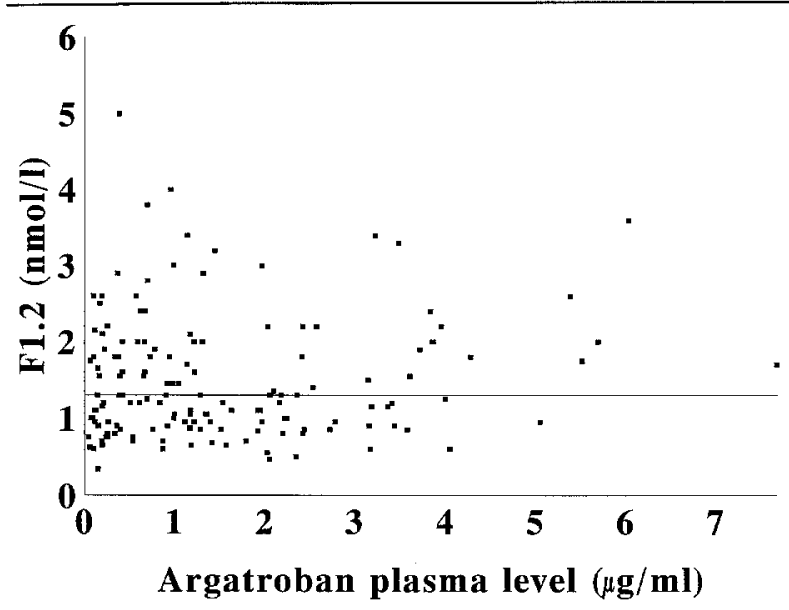

A

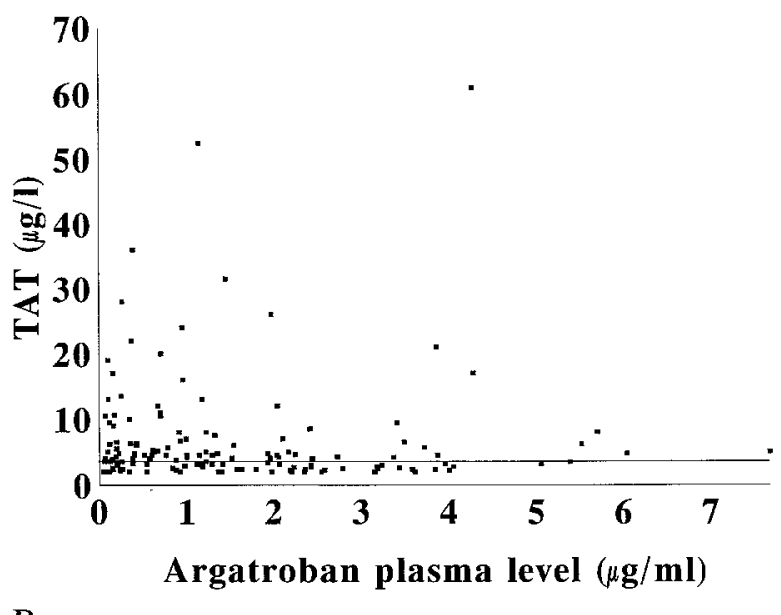

Fig. 2. The relationship between argatroban plasma level and the result of prothrombin fragment 1 and $2\left(F_{1.2}\right)$ and thrombinantithrombin III (TAT) measurements. A: $F_{1.2}$ in nmol/l; the upper normal limit is marked at $1.29 \mathrm{nmol} / \mathrm{l}$. B: TAT in $\mu \mathrm{g} / \mathrm{l} ;$; the upper normal limit is marked at $3.2 \mu \mathrm{g} / \mathrm{l}$.

Table 6A. Thrombin-antithrombin III complex (normal range 0.60-3.20 $\mu \mathrm{g} / \mathrm{L}$ ) by dosage group (median and range shown in brackets)

\begin{tabular}{cllllll}
\hline Time & N & Group B & N & Group C & N & Group D \\
\hline$-1 / 2 \mathrm{hr}$ & 8 & $4.1(2.2-18.5)$ & 9 & $2.6(2.0-10.5)$ & 11 & $3.9(2.0-11.0)$ \\
$1 \mathrm{hr}$ & 8 & $4.0(2.0-6.0)$ & 9 & $2.7(2.0-31.5)$ & 11 & $3.3(2.0-17.0)$ \\
$\mathbf{2} \mathrm{hr}$ & 7 & $5.0(2.4-12.0)$ & 8 & $2.3(2.0-4.2)$ & 11 & $4.8(2.4-161.0)$ \\
$24 \mathrm{hr}$ & 8 & $5.7(4.5-20.0)$ & 7 & $5.0(4.0-6.8)$ & 9 & $8.0(4.3-52.5)$ \\
$72 \mathrm{hr}$ & 7 & $3.2(2.4-13.0)$ & 7 & $2.6(2.0-4.2)$ & 8 & $3.8(2.9-11.0)$ \\
$73 \mathrm{hr}$ & 7 & $4.8(2.3-28.0)$ & 7 & $3.0(2.0-6.3$ & $8.5(2.2-36.0)$ \\
$74 \mathrm{hr}$ & 7 & $4.3(3.2-125.0)$ & 7 & $3.6(2.0-13.0)$ & 8 & $5.0(2.0-10.6)$ \\
\hline
\end{tabular}

Table $6 B$. Prothrombin fragments 1 and 2 (normal range 0.57-1.29 nmol/L) by dosage group (median and range shown in brackets)

\begin{tabular}{cllllrl}
\hline Time & N & Group B & N & Group C & N & Group D \\
\hline$-1 / 2 \mathrm{hr}$ & 8 & $0.93(0.43-2.10)$ & 9 & $1.10(0.45-1.50)$ & 11 & $1.30(0.55-3.40)$ \\
$1 \mathrm{hr}$ & 8 & $0.76(0.50-1.30)$ & 9 & $1.10(0.80-3.20)$ & 11 & $1.80(0.90-3.40)$ \\
$2 \mathrm{hr}$ & 7 & $1.30(0.60-2.20)$ & 8 & $1.35(0.90-2.20)$ & 11 & $2.00(0.60-7.00)$ \\
$24 \mathrm{hr}$ & 8 & $1.80(0.95-3.80)$ & 7 & $1.90(1.45-2.60)$ & 9 & $2.90(0.85-4.00)$ \\
$72 \mathrm{hr}$ & 7 & $0.70(0.47-1.05)$ & 7 & $1.05(0.90-1.30)$ & 8 & $1.35(0.85-2.10)$ \\
$73 \mathrm{hr}$ & 7 & $0.95(0.65-2.20)$ & 7 & $0.95(0.70-1.30)$ & 8 & $1.45(0.75-5.00)$ \\
$74 \mathrm{hr}$ & 7 & $1.00(0.70-11.25)$ & 7 & $0.90(0.62-1.80)$ & 8 & $1.13(0.34-2.50)$ \\
\hline
\end{tabular}

clearance, and important individual differences among patients frequently result in underdosing or overdosing.

Levels of $\mathrm{F}_{1,2}$ and TAT reflect the degree of prothrombin conversion and thrombin activity, respectively. Sampling was performed from separate peripheral vein punctures to avoid bias caused by the indwelling catheter $[35,36]$. These measurements indicate the systemic status of the coagulation system. Sampling from the great cardiac vein may have been more accurate, representing a less diluted effect on the local stimulus to the coagulation system. Absolute inhibition of thrombin generation by thrombin blockade remains a utopian concept, since argatroban requires an insignificant prothrombin conversion before it can display its antithrombin activity. Zoldhelyi et al. [37] recently reported their failure to block thrombin generation in patients, despite a 10,000 -fold molar excess of free hirudin over the thrombin-hirudin complex. Furthermore, these coagulation products are ex- 


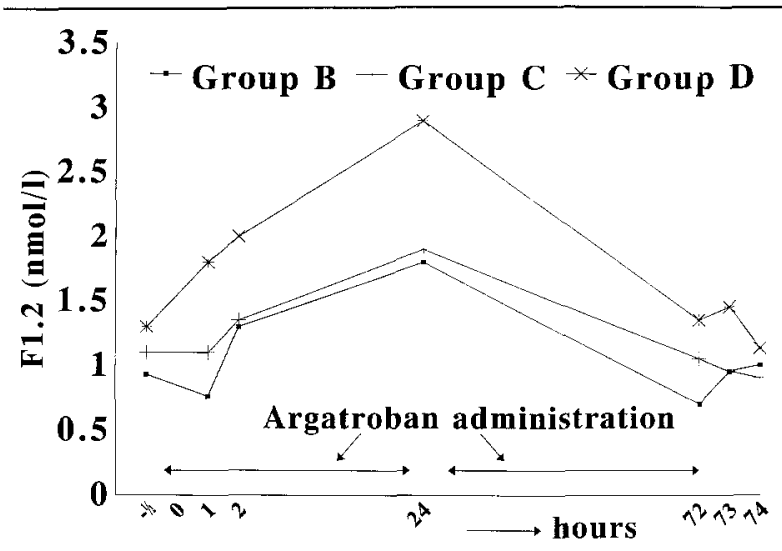

A

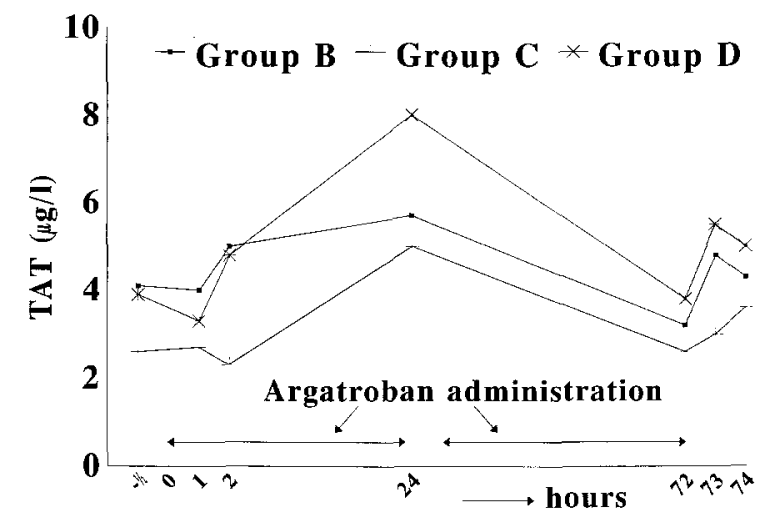

B

Fig. 3. The results of $F_{1.2}$ and TAT and measurements related to the infusion period. A: $F_{1.2}$ in nmol/l. B: TAT in $\mu g / l$.

tremely sensitive, to such an extent that only perfect atraumatic vein punctures can provide blood with unaffected, nonelevated levels.

Conceivably, a superior marker for thrombin blockade would be the fibrino-peptide A concentration [38]. This peptide is a product of thrombin-induced fibrinogen conversion and is therefore a direct mirror of the performance of nonblocked thrombin.

Rebound is described after cessation of IV argatroban infusion in patients with unstable angina pectoris $[24,39]$. In this study we did not uncover any clinical evidence for a rebound phenomenon in this cohort of patients. However, 24 hours after start of the infusion (just prior to sheath removal when the infusion was transiently interrupted), a substantial elevation of TAT and $\mathrm{F}_{12}$ levels was observed (Table 6; Figure 3). A lesser increase in TAT and $\mathrm{F}_{1.2}$ levels was detected 1 and 2 hours after the termination of the argatroban infusion (73 and 74 hours after the start of the infusion, respectively). This disparate response to cessation of argatroban administration may reflect the process of vessel wall passivation. It has to be emphasized that repetitive vein punctures within a short period of time may result in subsequent less optimal sampling quality, and therefore may demonstrate artifically elevated levels of TAT and $\mathrm{F}_{1.2}$.

\section{Conclusions}

This dose-finding study demonstates that argatroban infusion in patients undergoing PTCA may be safely administered, and produces an adequate and predictable level of anticoagulation. This trial provides useful and consistent information on the response of the coagulation system when exposed to argatroban. Indirect paramaters indicate ongoing thrombin conversion (prothrombin fragments 1 and 2) and activity (thrombin-antithrombin complex). An apparent safe and adequate dosage regimen was identified, and this dose is now undergoing further evaluation in a double-blind, double-dummy, 2:1 randomized and heparincontrolled study. The effect of argatroban on the restenosis process following coronary angioplasty must be determined in a larger investigation.

\section{Acknowledgments}

We greatly acknowledge the help of Yvonne Teunissen, Cardialysis B. V. Rotterdam, the Netherlands for her assistance in the preparation of this manuscript.

\section{References}

1. Ip JH, Fuster V, Israel D, Badimon L, Badimon J, Chesebro JH. The role of platelets, thrombin and hyperplasia in restenosis after coronary angioplasty. $J$ Am Coll Cardiol 1991;17:77B-88B.

2. Mann KG, Tracy PB, Nesheim ME. Assembly and function of prothrombinase complex on synthetic and natural membranes. Oates JA, Harviger J, Ross R, (eds). In: Interaction of Platelets with the Vessel Wall. Bethesda, MD: American Physiological Society, 1985; 47-57.

3. Heras M, Chesebro JH, Penny WJ, Bailey KR, Badimon L, Fuster V. Effects of thrombin inhibition on the development of acute platelet thrombus deposition during angioplasty in pigs: Heparin versus recombinant hirudin, a specific thrombin inhibitor. Circulation 1989;79:657-665.

4. Heras M, Chesebro JH, Webster MWI, et al. Hirudin, heparin and placebo during deep arterial injury in the pig. The in vivo role of thrombins in platelet-mediated thrombosis. Circulation 1990;82:1476-1484.

5. Fitzgerald DJ, Fitzgerald GA. Role of thrombin and thromboxane $A_{2}$ in reocclusion following coronary thrombolysis with tissue-type plasminogen activator. Proc Natl Acad Sei USA 1989;86:7585-7589.

6. Callas DD, Hoppensteadt D, Fareed J. Comparative studies on the anticoagulant and protease generation inhibitory actions of newly developed site-directed thrombin inhibitory drugs. Efegatran, argatroban, hirulog, and hirudin. Semin Thromb Hemost 1995;21:177-183.

7. Cheseboro JH, Badimon L. Fuster V. Importance of anti- 
thrombin therapy during coronary angioplasty. $J \mathrm{Am}$ Coll Cardiol 1991;17:96B-100B.

8. Badimon L, Badimon J, Lassila R,Heras M, Chesebro JH, Fuster V. Thrombin inhibition by hirudin decreases platelet thrombus growth on areas of severe vessel wall injury. $J$ Am Coll Cardiol 1989;13:145A.

9. Umemura $\mathrm{K}$, Kawai $\mathrm{H}$, Ishihara $\mathrm{H}$, Nakashima M. Inhibitory effect of clopidogrel, vapiprost and argatroban on the middle cerebral artery thrombosis in the rat. Jpn J Pharmacol 1995;67:253-825.

10. Suzuki S, Sakamoto S, Adachi K, et al. Effect of argatroban on thrombus formation during acute coronary occlusion after balloon angioplasty. Thromb Res 1995;77:369-373.

11. Valji J, Arun K, Bookstein JJ. Use of a direct thrombin inhibitor (argatroban) during pulse-spray thrombolysis in experimental thrombosis. $J$ Vasc Interv Radiol 1995;6: 91-95.

12. Berry CN, Girard D, Lochot S, Lecoffre C. Antithrombotic actions of argatroban in rat models of venous, 'mixed' and arterial thrombosis, and its effects on the tail transection bleeding time. Br J Pharmacol 1994;113:1209-1214.

13. Nishiyama $H$, Umemura $K$, Saniabadi AR, Takiguchi $Y$, Uematsu T, Nakashima M. Enhancement of thrombolytic efficacy of tissue-type plasminogen activator by adjuvants in the guinea pig thrombosis model. Eur J Pharmacol 1994; 264:191-198.

14. Sasaki Y, Morii S, Yamashita T, Yamamoto J. Antithrombotic effect of argatroban on the pial vessels of the rat: $\mathrm{A}$ study with $\mathrm{He}-\mathrm{Ne}$ laser-induced thrombus formation. Haemostasis 1993;23:104-111.

15. Yamashita T, Yamamoto J, Sasaki Y, Matsuoka A. The antithrombotic effect of low molecular weight synthetic thrombin inhibitors, argatoban and PPACK, on He-Ne laser-induced thrombosis in rat mesenteric microvessels. Thromb Res 1993;69:93-100.

16. Jackson CV, Wilson HC, Growe VG, Shuman RT. Reversible tripeptide thrombin inhibitors as adjunctive agents to coronary thrombolysis: A comparison with heparin in a canine model of coronary artery thrombosis. $J$ Cardiovasc Pharmacol 1993;21:587-594.

17. Tomoda H. Experimental evaluation of coronary thrombodynamics and effects of pharmacological interventions in acute coronary syndromes Jpn Circ $J$ 1992;56:1184-1190.

18. Matsuo T, Kario K, Kodama K, Okamoto S. Clinical application of the synthetic thrombin inhibitor, argatroban (MD805). Semin Thromb Hemost 1992;18:155-160.

19. Schneider J. Heparin and the thrombin inhibitor argatroban enhance fibrinolysis by infused or bolus-injected saruplase ( $r$-scu-PA) in rabbit femoral artery thrombosis. Thromb Res 1991;64:677-689.

20. Jang IK, Gold HK, Ziskind AA, Leinbach RC, Fallon JT. Collen D. Prevention of platelet-rich arterial thrombosis by selective thrombin inhibition. Circulation 1990;81:219-225.

21. Matsuo T, Yamada T, Yamanashi T, Ryo R. Anticoagulant therapy with MD 805 of a hemodialysis patient with heparin-induced thrombocytopenia. Thromb Res 1990;58: 663-666.

22. Matsuo T, Yamada T, Yamanashi T, Komada K. Choice of anticoagulant in congenital antithrombin III-deficient patient with chronic renal failure undergoing regular haemodialysis. 'Clin Lab Haemat 1989;11:213-219.
23. Clarke RJ, Mayo G, Fitzgerald GA, Fitzgerald DJ. Combined administation of aspirin and a specific thrombin inhibitor in man. Circulation 1991;83:1510-1518.

24. Gold HK, Torres FW, Garabedian HD, et al. Evidence for a rebound coagulation phenomenon after cessation of a 4-hour infusion of a specific thrombin inhibitor in patients with unstable angina pectoris. I Am Coll Card 1993;21:1039-1047.

25. Serruys PW, de Jaegere P, Kiemeneij F, et al. A comparison of balloon-expandable stent implantation with balloon angioplasty in patients with coronary artery disease. $N$ Engl J Med 1994;331:489-495.

26. Serruys PW, Foley DP, de Feyter PJ, eds. Quantitative Coronary Angiography in Clinical Practice. Dordrecht: Kluwer Academic Publishers, 1994.

27. Blackburn H, Keys A, Simonson E, Rautaharju P, Punsar $\mathrm{S}$. The electrocardiograms in population studies: A classification system. Circulation 1960;21:1160-1175.

28. Hull R, Hirsch J, Jay R, et al. Different intensities of oral anticoagulant therapy in the treatment of proximal-vein thrombosis. N Engl J Med 1982;307:1676-1681.

29. TIMI Study Group. The thrombolysis in myocardial infarction (TIMI) trial: Phase I findings. $N$ Engl J Med 1985; 213:982-936.

30. Chesebro JH, Badimon L, Fuster V. Importance of antithrombin therapy during coronary angioplasty. $J$ Am Coll Cardiol 1991;17:96B-100B.

31. Wilentz JR, Sanborn TA, Haudenschild CC, Valeri CR, Ryan TJ, Faxon DP. Platelet accumulation in experimental angioplasty: Time course and relation to vaseular injury. Circulation 1987;75:636-642.

32. Groves H, Kinlough-Rathbone RL, Mustard JF. Development of nonthrombogenicity of injured rabbit aortas despite inhibition of platelet adherence. Arteriosclerosis 1986;6: 189-195.

33. Steele PM, Chesebro JH, Stanson AW, et al. Balloon angioplasty: Natural history of the pathophysiological response to injury in a pig model. Circ Res 1985;57:105-112.

34. Avendano A, Ferguson JJ. Comparison of Hemochron and HemoTec activated coagulation time target values during percutaneous transluminal coronary angioplasty $J \mathrm{Am}$ Coll Cardiol 1994;23:907-910.

35. Huisveld IA, van den Burg PJM, Meijer P, et al. Catheter unsuitable for the study of turn-over products of coagulation, fibrinolysis and platelet activation. Fibrinolysis 1992; 6:78-80.

36. van Genderen PJJ, Gomes M, Stibbe J. The reliability of Hickman catheter blood for the assessment of activation markers of coagulation and fibrinolysis in patients with hematological malignancies. Thrombo Res 1994;73:247-254.

37. Zoldhelyi P, Bichler J, Owen GO, et al. Persistent thrombin generation in humans during specific thrombin inhibition with hirudin. Circulation 1994;90:2671-2678.

38. Bos AA van den, Deckers JW, Heyndrickx GR, et al. Safety and efficacy of recombinant hirudin (CGP 39 393) versus heparin in patients with stable angina undergoing coronary angioplasty. Circulation 1993;88:2058-2066.

39. Willerson JT, Casscells W. Thrombin inhibitors in unstable angina: Rebound or continuation of angina after argatroban withdrawal? J Am Coll Cardiol 1993;21:1048-1051.

40. Braunwald E. Unstable angina pectoris. A classification. Circulation 1989;89:410. 